\title{
广东古兒山自然保护区茨类植物多样性对植被 不同演替阶段的生态响应
}

\section{严岳鸿 易绮斐 黄忠良 邢福武*}

(中国科学院华南植物研究所, 广州 510650)

摘要 : 蒴类植物是最早登陆的维管植物, 至今仍然是生态系统初级生产力的重要组成部分。它们一方面可以通过 改造生态环境影响森林群落发生和发展的过程, 另一方面由于它们对生态因子变化的敏感性, 其组成的多样性及 其对环境的适应组合也随着森林群落发生和发展而不断变化。为了解䓲类植物在群落演替的各个阶段的种类组 成、物种多样性格局演变规律及其适应方式的选择，本文选择广东古兒山自然保护区中的草丛、灌丛、次生常绿阔 叶林和地带性南亚热带季风常绿阔叶林 (以下相对简称 原生林”) 等 4 个处于不同演替阶段的植被类型中的䓲类 植物群落进行研究。每一植被类型中选取 4 个 $5 \mathrm{~m} \times 5 \mathrm{~m}$ 代表性小样方进行取样调查, 对其主要数量特征、群落的 $\alpha$ 多样性、 $\beta$ 多样性、不同群落间的相似性系数和䓲类植物的种类性质进行了分析。结果表明: 随着群落演替的进 展 草丛、灌丛、次生林和原生林各阶段植被中：(1) 群落之间的 $\beta$ 多样性指数逐渐增大，而相似性指数依次降低; (2) 蕨类植物的物种丰富度依次增大, 而群落的多样性指数、生态优势度和均匀度并不伴随着群落的丰富度呈明显 的规律性变化; ; 3 具革质叶的硕类、阳生蕨类和进行无性繁殖的偋类植物在各阶段所占的比例和重要值比重逐渐

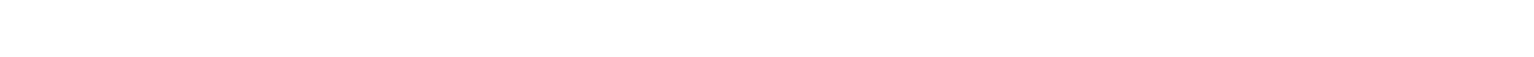
以上结果显示蕨类植物的物种组成及其适应环境的能力对不同植被环境具有比较显著的指示作用; 在植被保护和 植被恢复的实践中，森林乔木树种与林下偋类植物之间的相生相克作用是值得关注的。

关键词 : 偋类植物, $\alpha$ 多样性, $\beta$ 多样性, 生态演替, 恢复生态学

中图分类号 : Q948 文献标识码 : A 文章编号 : 1005-0094(2004)03-0339-09

\section{The ecological response of fern diversity to vegetation succession in Gu- doushan Nature Reserve , Guangdong}

YAN Yue-Hong , YI Qi-Fei , HUANG Zhong-Liang , XING Fu-Wu *

South China Institute of Botany, Chinese Academy of Sciences , Guangzhou 510650

Abstract : Ferns were the first terricolous vascular plants , and still comprise an important part of primary productivity of ecosystems. On the one hand, they make a great contribution to the processes of dynamics and development of the forest community ; on the other hand, because of their sensitivity to change in ecological factors , the composition of the fern community and its adaptations change with the development of forest community. In order to understand the changes of composition and the adaptability of ferns in the process of vegetation succession , a survey on a successional series of vegetation was carried out in $\mathrm{Gu}$ doushan Nature Reserve , $112^{\circ} 52^{\prime} 30^{\prime \prime}-113^{\circ} 03^{\prime} 25^{\prime \prime} \mathrm{E}$ and $22^{\circ} 5^{\prime} 00^{\prime \prime}-22^{\circ} 21^{\prime} 15^{\prime \prime} \mathrm{N}$, which is located in the south-central area of Guangdong Province, China. Four quadrats of $100 \mathrm{~m}^{2}$ each $(4 \times 5 \mathrm{~m} \times 5 \mathrm{~m})$ were located in grassland, shrub, secondary forest dominated by heliophytic trees, and typical southern subtropical monsoon evergreen broadleaf forest ( hereafter abbreviated as" primary forest”) dominated by shade-adapted trees. The importance value $(I V)$ of each fern species and the index of $\alpha$ - and $\beta$-diversity of communities in the process of vegetational succession were calculated. Changes in leaf characteristics , shade tolerance and reproductive strategy of ferns in the course of vegetation succession were analyzed. The results showed that, with the development of communities from grassland to shrub , to secondary forest and to primary forest , (1) the index of $\beta$-diversity among different fern communities increased, but 
the index of similarity among different communities decreased ; (2) species richness increased, but the Shannon-Weiner index , Simpson index and index of evenness did not increase with the change in richness ; (3) proportion of ferns with leathery leaves decreased gradually, but the proportion of ferns with herbaceous leaves increased, and ferns with membranous leaves appeared in the last stages ; 4 ) the proportion of shade-tolerant ferns increased gradually , and sun-tolerant ferns decreased ; $(5)$ the proportion of ferns with sexual reproduction increased gradually, while the ferns with asexual reproduction decreased. The results also indicate that the ferns and their adaptation to the environment are useful indexes that reflect the change of the environment in different vegetational stages. More attention should be paid to the interaction between ferns and trees in the practice of restoration and conservation of biodiversity.

Key words : pteridophytes , $\alpha$-diversity , $\beta$-diversity , ecological succession , restoration ecology

蕨类植物是地球上普遍分布、起源古老而又十 分独特的类群, 在漫长的进化历程中, 藓类植物形成 了多样的生态类型和适应方式。一方面, 在众多的 生物群落中, 䓲类植物是草本层中的优势层片, 是森 林生态系统初级生产力的重要组成部分 (郭泉水, 1998）对改变森林环境具有重要的生态作用, 并直 接影响着森林群落发生和发展的过程。在群落演替 的早期阶段, 粗类植物可以作为裸地的先锋植物入 侵, 进而形成大面积的单优种群, 政变土壤环境和理 化性质, 并大量分泌他感物质, 对以后即将进入该地 的植物种类进行初步篮选 (Johnson-Maynard et al. , 1997 ，1998)。在群落演替的发展阶段,鲧类植物可 能通过改变群落的林窗格局和影响群落土壤种子库 来改变和影响群落的演替 (张笃见等, 1999)。此 外, 获类植物对维持顶极群落或成熟群落的群落结 构和环境基质具有重要的生态作用 ( Soares , 1999; Yorks et al. , 2000)。另一方面, 䓲类植物是最早登 陆的维管植物, 对环境的适应能力较差, 对环境的变 化比较敏感, 光照、温度、水分、土壤和伴生物种等生 态因子的变化往往会造成藓类植物种类组成及其适 应方式的差异。

植物群落的演替过程就是群落中的物种组成不 断发生变化、更替及群落环境中生化的过程。有关 群落演替进程中种子植物物种多样性的变化及其适 应方式的选择已有很多报道，但有关茨类植物在群 落演替的各个阶段的种类组成、物种多样性格局演 变规律及其适应方式的选择尚无明确结论，仅有少 量伴随着其他种子植物研究的零散报道 (张管见 等, 1999)。开展不同演替阶段茨类植物物种多样 性格局动态变化的专门研究, 不仅是植物群落学和 恢复生态学中的重要内容, 而且对获类植物的保护 生物学研究具有重要意义。本文拟通过对广东古兒
山自然保护区植被不同演替阶段偋类植物物种多样 性变化的研究 探讨藓类植物多样性在群落演替进 程中的一般变化趋势及其生态响应方式。

\section{1 样地概况与数据处理}

\section{1 样地概况}

广东古兒山自然保护区位于广东省中南部江门 市地区 地处 $112^{\circ} 52^{\prime} 30^{\prime \prime}-113^{\circ} 03^{\prime} 25^{\prime \prime} \mathrm{E}, 22^{\circ} 5^{\prime} 00^{\prime \prime}$ $22^{\circ} 21^{\prime} 15^{\prime \prime} \mathrm{N}$ 总面积达 $11567.5 \mathrm{hm}^{2}$, 属南亚热带温 暖湿润的海洋性气候。年均温约 $22^{\circ} \mathrm{C}, 1$ 月平均温 $10.1-13.4^{\circ} \mathrm{C}$; 雨量充沛, 多年平均降水量 $1789-$ $2250 \mathrm{~mm}, 4-9$ 月为雨季, 10 月至翌年 3 月为旱季, 干湿季节明显。境内地貌类型属于中、低山丘陵地 形复杂 最高峰狮子头海拔 $986 \mathrm{~m}$ 。土壤类型为酸 性地带性赤红壤, 母岩基质为花岗岩。

当地植被自然演替序列从次生裸地开始, 历经 草丛、灌丛、次生常绿榈叶林 (以下简称次生林) 到 地带性的南亚热带季风常绿阔叶林 (与次生林相区 别，以下简称原生林）。本文所选取的样地位于古 兒山自然保护区东北部海拔 $600 \mathrm{~m}$ 以下的山谷侧 坡。草丛主要由禾本科和蕨类植物组成, 如鹧坞草 (Eriachne pallescens)、芒 (Miscanthus sinensis)、芒其 ( Dicranopteris pedata)、野古草 (Arundinella anomala)、鳞籽莎 ( Lepidosperma chinensis) 等。样地海拔 $25-50 \mathrm{~m}$, 坡度 $15^{\circ}-25^{\circ}$,生境开阔。当地的草丛 植被多为经过强而持续的人为干扰所形成的干扰顶 极植被, 当人为干扰停止后, 草丛继续演替成灌草 丛、灌丛。

灌丛是以灌木组成为主的植被类型，主要有岗 松 (Baeckea frutescens)、桃金娘( Rhodomyrtus tomento$s a$ )、野牡丹 ( Melastoma caudidum)、鸭脚木( Schefflera octophylla) 、米碎花 (Eurya chinensis)、大头茶 
(Gordonia axillaris)、乌毛蔴 (Blechnum orientale)、金 毛狗 (Cibotium barometz) 等。样地海拔 30-50 m、 坡度 $20^{\circ}-30^{\circ}$,生境开润。

次生林主要由一些阳性的阔叶树种组成，如鸭 脚木、三叉苦 (Euodia lepta) 、酒饼勒 (Acronychia pedunculata)、红花荷 (Rhodoleia championi) 、荷木 ( Schima superba)、藜蒴 ( Castanopsis fissa) 、山杜英 (Elacocarpus sylvestris) 等 样地位于海拔高度为 400 $-600 \mathrm{~m}$ 、坡度 $30^{\circ}-40^{\circ}$ 的山谷侧坡, 群落郁闭度 $0.6-0.8$ 经常遭受一定的人为干扰。

原生林是与次生林相对而言 (本地现在并不存 在真正的原生林)，指近三四十年间人为破坏较少 的地带性常绿润叶次生林，主要优势树种有荷木、锥 栗 (Castanopsis chinensis) 、山杜英、阿丁枫 (Altingia chinensis) 和柯属 (Lithocarpus spp. )、润楠属 (Machilus spp. )、厚壳桂属 (Cryptocarya spp. ) 的植物，样地 海拔 500-600 m 坡度 $30^{\circ}-40^{\circ}$ 群落有闭度 $0.8-$ 0.9 。

根据蕨类植物的生活习性和保护区的自然条 件，以 空间代替时间”的方法 (Daubenmire，1981) 分别在草丛、灌丛、次生林和原生林 4 个不同演替系 列中，沿山脊、山脊侧坡、山谷侧坡至山谷 4 个不同 的坡位选取 4 个 $5 \mathrm{~m} \times 5 \mathrm{~m}$ 的代表性小样方，逐一记 录样方中每种烣类植物的名称、数量和盖度, 及样方 的主要环境条件。样方调查结果见表 1 。

\section{2 数据处理}

多度 ( abundance) 是指物种个体数目的多少。 对于群落中根状茎短而直立或斜升的蕨类植物，如 黑杪椤 (Gymnosphaera podophylla) 等, 每一植株记数 为一株。根状茎长而横走的蕨类, 如石韦 (Pyrrosia lingua $)$ 等, 在自然条件下, 通过根状茎延长产生不 定根和叶片或羽片，横走的根状茎断裂或失去功能 后, 形成多个遗传结构一致的新个体, 即分株, 具有 无性系生长的习性（董鸣，1996）。对具有这种生长 习性的蕨类植物的记数方法是每一无性系生长的分 株为一株(张笃见等,1999)。对于草本群落的重要 值 (importance value, $I V$ ) 的计算, 文中以种群的相 对盖度代替相对显著度, 即重要值 $(I V \%)=$ 相对多 度 $(A \%)+$ 相对频度 $(F \%)+$ 相对盖度 $(C \%)$ ( 孙儒 泳等,1993)。

物种丰富度指数 $: R_{0}=S$

优势度指数为 Simpson 指数 (马克平等 ,1994)：

$$
D=1-\sum P_{i}^{2}
$$

多样性指数 Shannon-Wiener 指数 ( Pielou, 1975 ) :

$H^{\prime}=-\sum P_{i} \ln P_{i}$

物种均匀度指数采用 Pielou 的均匀度指数 (马 克平 ,1994) :

$$
\begin{aligned}
& J_{s w}=\left(-\sum P_{i} \ln P_{i}\right) / \ln S \\
& J_{g i}=\left(1-\sum P_{i}^{2}\right) /(1-1 / S)
\end{aligned}
$$

$\beta$ 多样性指数采用 Whittaker 指数 (1960)：

$\beta_{W}=S / m a-1$

相似性系数采用 Jaccard 指数 (Whittaker, $1972)$ :

$$
C_{J}=j /(a+b-j)
$$

式中 $S$ 为研究系统中的橧类种类总和, 即丰富度指 数; $P_{i}$ 为种 $i$ 的个体数占所有种的个体数的比率; $m a$ 为各样方或样本的平均物种数; $a, b$ 为样地 $\mathrm{A} 、 \mathrm{~B}$ 的物种数 $j$ 为样地 A、B 共有的物种数。

\section{2 结果与分析}

2.1 植被演替过程中蕨类植物物种的更替及其主 要数量特征的变化

$\beta$ 多样性指数是指沿着环境梯度,物种替代的 速度和不同群落间物种组成的差异。不同群落或某 环境梯度不同点之间共有物种越少, $\beta$ 多样性指数 越大; 共有物种越多, 相似性指数越大。由表 2 可 知, 随着演替的进展，从各植被恢复较低级阶段到较 高级阶段的过程中, 群落之间的 $\beta$ 多样性指数依次 升高，演替时间距离相差越远， $\beta$ 多样性指数越大; 而相似性指数依次降低, 表明演替时间距离相差越 近，相似性指数越大。在植被的演替过程中，由于硕 类植物对环境适应能力的差异，出现了草丛植被与 原生林植被中种类完全不同的极端情况 ( $\beta$ 多样性 指数达到最大值 Jaccard 相似性指数达到最小值)。 这表明, 随着演替的发生和发展, 群落之间的差异越 来越大, 群落之间的共有物种越来越少。也就是说， 无论演替早期起始物种是什么, 群落都会向着地带 性顶极植被的方向发展。由表 1 可知, 䓲类植物在 草丛、灌丛、次生林和原生林中各样方的总盖度依次 大致呈下降趋势, 而重要值则呈上升趋势, 表明随着 演替的发展和乔灌木树种的侵入，蕨类植物在各植 被类型中的地位发生了变化。

草丛中的莍类植物种类主要是一些阳性、耐旱 
表 1 植被演替过程中蕨类植物群落的物种变化和主要数量特征

Table 1 The fern composition and community characteristics in the succession process of vegetation

\begin{tabular}{|c|c|c|c|c|c|c|}
\hline $\begin{array}{l}\text { 种类 } \\
\text { Species }\end{array}$ & $\begin{array}{c}\text { 多度 } \\
\text { Abundance }\end{array}$ & $\begin{array}{c}\text { 盖度 } \\
\text { Coverage } \\
(\%)\end{array}$ & $\begin{array}{c}\text { 重要值 } \\
\text { Importance value } \\
(I V)\end{array}$ & $\begin{array}{l}\text { 耐荫性 } \\
\text { Shade } \\
\text { tolerance }\end{array}$ & $\begin{array}{c}\text { 叶质 } \\
\text { Leaf } \\
\text { characteristics }\end{array}$ & $\begin{array}{l}\text { 繁殖策略 } \\
\text { Repproduction } \\
\text { strategy }\end{array}$ \\
\hline \multicolumn{7}{|l|}{ 草丛 Grassland } \\
\hline 1. 扇叶铁线蕨 Adiantum flabellatum & 12 & 5 & 9.6287 & - & $\mathrm{H}$ & S \\
\hline 2. 乌毛薕 Blechnum orientale & 10 & 60 & 13.9521 & + & $\mathrm{L}$ & S \\
\hline 3. 芒其 Dicranopteris pedata & 332 & 220 & 75.8121 & + & $\mathrm{L}$ & $\mathrm{S} / \mathrm{A}$ \\
\hline 4. 双唇蕨 Lindsaea ensifolia & 38 & 10 & 20.2945 & 0 & $\mathrm{H}$ & $\mathrm{S} / \mathrm{A}$ \\
\hline 5. 小叶海金沙 Lygodium scandens & 5 & 20 & 10.3297 & + & $\mathrm{H}$ & $\mathrm{S} / \mathrm{A}$ \\
\hline 6. 铺地蜈蚣 Palhinhaea cernua & 53 & 95 & 28.3162 & + & $\mathrm{H}$ & $\mathrm{S} / \mathrm{A}$ \\
\hline 小计 Total & 450 & 410 & 158.3333 & & & \\
\hline \multicolumn{7}{|l|}{ 灌丛 Shrub } \\
\hline 1. 扇叶铁线鰀 Adiantum flabellatum & 61 & 16 & 34.7074 & - & $\mathrm{H}$ & $\mathrm{S}$ \\
\hline 2. 乌毛藓 Blechnum orientale & 20 & 35 & 31.1701 & + & $\mathrm{L}$ & $\mathrm{S}$ \\
\hline 3. 金毛狗 Cibotium barometz & 15 & 60 & 16.3495 & 0 & $\mathrm{~L}$ & $\mathrm{~S}$ \\
\hline 4. 芒其 Dicranopteris pedata & 42 & 35 & 25.7584 & + & $\mathrm{L}$ & $\mathrm{S} / \mathrm{A}$ \\
\hline 5. 双唇蔴 Lindsaea ensifolia & 19 & 9 & 20.0935 & 0 & $\mathrm{H}$ & $\mathrm{S} / \mathrm{A}$ \\
\hline 6. 小叶海金沙 Lygodium scandens & 3 & 5 & 9.2337 & + & $\mathrm{H}$ & $\mathrm{S} / \mathrm{A}$ \\
\hline 7. 狭叶紫其 Osmunda angustifolia & 1 & 1 & 8.5665 & + & $\mathrm{L}$ & S \\
\hline 8. 铺地蜈蚣 Palhinhaea cernua & 33 & 85 & 21.2499 & + & $\mathrm{H}$ & $\mathrm{S} / \mathrm{A}$ \\
\hline 9. 深绿卷柏 Selaginella doederleinii & 30 & 5 & 12.8194 & - & $\mathrm{H}$ & $\mathrm{S} / \mathrm{A}$ \\
\hline 10. 乌蕨 Stenoloma chusanum & 2 & 1 & 8.6993 & + & $\mathrm{H}$ & $\mathrm{S} / \mathrm{A}$ \\
\hline 11. 假芒其 Sticherus laevigatus & 25 & 80 & 19.6855 & + & $\mathrm{H}$ & $\mathrm{S} / \mathrm{A}$ \\
\hline 小计 Total & 251 & 332 & 208.3333 & & & \\
\hline \multicolumn{7}{|l|}{ 次生林 Secondary forest } \\
\hline 1. 扇叶铁线蕨 Adiantum flabellatum & 20 & 6 & 20.6095 & - & $\mathrm{H}$ & $\mathrm{S}$ \\
\hline 2. 崇澍颜 Cheniopteris harlandii & 50 & 25 & 36.7404 & - & $\mathrm{L}$ & $\mathrm{S} / \mathrm{A}$ \\
\hline 3. 金毛狗 Cibotium barometz & 2 & 5 & 9.5562 & 0 & $\mathrm{H}$ & $\mathrm{S}$ \\
\hline 4. 大芒其 Dicranopteris ampla & 38 & 65 & 34.2523 & 0 & $\mathrm{~L}$ & $\mathrm{~S} / \mathrm{A}$ \\
\hline 5. 铁芒其 Dicranopteris linearis & 8 & 10 & 11.3417 & - & $\mathrm{H}$ & $\mathrm{S} / \mathrm{A}$ \\
\hline 6. 柄叶鳞毛藓 Dryopteris podophylla & 8 & 2 & 9.8352 & 0 & $\mathrm{~L}$ & $\mathrm{~S}$ \\
\hline 7. 团叶鳞始偋 Lindsaea orbiculata & 6 & 1 & 9.3655 & 0 & $\mathrm{H}$ & $\mathrm{S} / \mathrm{A}$ \\
\hline 8. 华南紫其 Osmunda vachellii & 1 & 5 & 9.4156 & + & $\mathrm{L}$ & $\mathrm{S}$ \\
\hline 9. 钝羽金星蕨 Parathelypteris anguriloba & 68 & 37 & 49.8653 & - & $\mathrm{H}$ & S \\
\hline 10. 镰叶瘤足偋 Plagiogyria distinctissima & 4 & 5 & 9.8375 & - & $\mathrm{H}$ & $\mathrm{s}$ \\
\hline 11. 深绿卷柏 Selaginella doederleinii & 17 & 11 & 29.4626 & - & $\mathrm{H}$ & $\mathrm{S} / \mathrm{A}$ \\
\hline 12. 粗叶卷柏 Selaginella trachyphylla & 15 & 5 & 11.3847 & - & $\mathrm{H}$ & $\mathrm{S} / \mathrm{A}$ \\
\hline 小计 Total & 237 & 177 & 241.6667 & & & \\
\hline \multicolumn{7}{|l|}{ 原生林 Primary forest } \\
\hline 1. 大片复叶耳薕 Arachniodes cavalerii & 33 & 40 & 31.7888 & - & $\mathrm{L}$ & S \\
\hline 2. 崇澍颜 Cheniopteris harlandii & 270 & 55 & 47. 1776 & - & $\mathrm{L}$ & $\mathrm{S} / \mathrm{A}$ \\
\hline 3. 金毛狗 Cibotium barometz & 11 & 30 & 12.6387 & 0 & $\mathrm{H}$ & $\mathrm{s}$ \\
\hline 4. 镰羽贯众 Cytomium balansae & 1 & 1 & 8.5131 & - & $\mathrm{L}$ & $\mathrm{S}$ \\
\hline 5. 柄叶鳞毛锁 Dryopteris podophylla & 6 & 2 & 8.9215 & 0 & $\mathrm{~L}$ & S \\
\hline 6. 黑桫椤 Gymnosphaera podophylla & 19 & 90 & 28.7824 & - & $\mathrm{H}$ & $\mathrm{s}$ \\
\hline 7. 团叶鳞始蕨 Lindsaea orbiculata & 16 & 2 & 17. 8266 & 0 & $\mathrm{H}$ & $\mathrm{S} / \mathrm{A}$ \\
\hline 8. 钝羽金星蕨 Parathelypteris anguriloba & 16 & 7 & 18.4393 & - & $\mathrm{H}$ & $\mathrm{s}$ \\
\hline 9. 镰叶瘤足蕨 Plagiogyria distinctissima & 4 & 6 & 17. 6307 & - & $\mathrm{H}$ & S \\
\hline
\end{tabular}


表 1 (续) Table 1 ( continued)

\begin{tabular}{|c|c|c|c|c|c|c|}
\hline $\begin{array}{l}\text { 种类 } \\
\text { Species }\end{array}$ & $\begin{array}{c}\text { 多度 } \\
\text { Abundance }\end{array}$ & $\begin{array}{c}\text { 盖度 } \\
\text { Coverage } \\
(\%)\end{array}$ & $\begin{array}{c}\text { 重要值 } \\
\text { Importance value } \\
(I V)\end{array}$ & $\begin{array}{c}\text { 耐荫性 } \\
\text { Shade } \\
\text { tolerance }\end{array}$ & $\begin{array}{c}\text { 叶质 } \\
\text { Leaf } \\
\text { characteristics }\end{array}$ & $\begin{array}{c}\text { 繁殖策略 } \\
\text { Reproduction } \\
\text { strategy }\end{array}$ \\
\hline 10. 全缘凤尾蕨 Pteris insignis & 8 & 7 & 17.9819 & - & $\mathrm{H}$ & $\mathrm{S}$ \\
\hline 11. 粗叶卷柏 Selaginella trachyphylla & 109 & 25 & 34.2959 & - & $\mathrm{H}$ & $\mathrm{S} / \mathrm{A}$ \\
\hline 12. 深绿卷柏 Selaginella doederleinii & 10 & 2 & 9.1502 & - & $\mathrm{H}$ & $\mathrm{S} / \mathrm{A}$ \\
\hline 13. 广西长筒蕨 Selenodesmium siamense & 80 & 5 & 13.5201 & - & M & $\mathrm{S} / \mathrm{A}$ \\
\hline
\end{tabular}

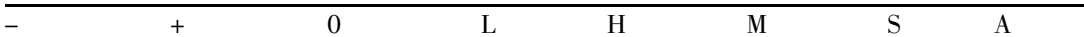

- Shade ferns ;+ Sun ferns, 0 Shade enduring ferns ; L :Leathery leaf ;H : Herbaceous leaf ;M : Membranous leaf ; : Sexual ;A :Asexual

表 2 植被演替过程中群落间的 $\boldsymbol{\beta}$ 多样性与相似性

Table 2 The indexes of $\beta$-diversity and similarity in the succession process of vegetation

\begin{tabular}{|c|c|c|c|c|c|c|c|c|}
\hline \multirow{2}{*}{$\begin{array}{c}\text { 植被类型 } \\
\text { Vegetation type }\end{array}$} & \multicolumn{2}{|c|}{$\begin{array}{c}\text { 草丛 } \\
\text { Grassland }\end{array}$} & \multicolumn{2}{|c|}{$\begin{array}{l}\text { 灌丛 } \\
\text { Shrub }\end{array}$} & \multicolumn{2}{|c|}{$\begin{array}{c}\text { 次生林 } \\
\text { Secondary forest }\end{array}$} & \multicolumn{2}{|c|}{$\begin{array}{c}\text { 原生林 } \\
\text { Primary forest }\end{array}$} \\
\hline & $\beta_{w}$ & $C_{\text {Jaccard }}$ & $\beta_{w}$ & $C_{\text {Jaccard }}$ & $\beta_{w}$ & $C_{\text {Jaccard }}$ & $\beta_{w}$ & $C_{\text {Jaccard }}$ \\
\hline 灌丛 Shrub & 0.2941 & 0.5455 & 0 & 1 & & & & \\
\hline 次生林 Secondary forest & 0.8889 & 0.0588 & 0.2121 & 0.15 & 0 & 1 & & \\
\hline
\end{tabular}

蕨类,有双唇蕨 (Lindsaea ensifolia) 、小叶海金沙 (Lygodium scandens) 等 6 种。其中芒萁、铺地蜈蚣 (Palhinhaea cernua $)$ 是中国热带亚热带广泛分布的 蕨类植物，在样方中多度大、出现频度高、重要值较 大, 在群落中扮演着重要角色, 是草丛中的优势蕨 类。它们不仅是中国南方荒地中的重要拓荒者, 而 且还对草地的养分循环和能量流动具有重要意义 ( 管东生 ,1996)。

在灌丛中, 以扇叶铁线蕨 (Adiantum flabellatum)、乌毛蕨、芒萁等为优势蕨类。草丛中出现的 蕨类虽然全部可以继续在灌丛中生存，但草丛中的 阳性优势种如芒其、铺地蜈蚣等开始衰退，而阴性种 类扇叶铁线蕨和能耐受一定荫蔽的乌毛烣则得到了 发展 随着一些阳性灌木的侵入, 其他阴性或能耐受 一定荫蔽的蕨类如金毛狗 (Cibotium barometz)、假芒 其 (Sticherus laevigatus)、狭叶紫其(Osmunda angustifolia)、深绿卷柏 (Selaginella doederleinii) 等开始在 群落中出现。

在郁闭度较大的次生林下, 草丛中出现的蕨类 除了扇叶铁线蕨外其他种类均已消失;灌丛中出现 的金毛狗由于耐荫性较差已开始衰退，而耐荫性强 的深绿卷柏则继续保持一定的优势, 其他种类均不 在样方中出现. 随着乔木树种的侵入和林冠层的发
展, 大量的阴性蕨类开始在样方中出现, 如崇澍蕨 (Cheniopteris harlandii)、铁芒其 (Dicranopteris linearis)，钝羽金星蕨( Parathelypteris anguriloba)、镰叶 瘤足蕨 (Plagiogyria distinctissima) 、团叶鳞始蕨 (Lindsaea orbiculata)、粗叶卷柏 (Selaginella trachyphylla) 等,其中阴性蕨类崇澍蕨、钝羽金星蕨 (Parathelypteris anguriloba) 和耐荫性蕨类大芒其 (Dicranopteris ampla) 发展成为次生林下的优势蕨 类。

在林分郁闭度大、人为干扰程度较小、发育时间 较长的原生林中, 所有在草丛中出现的种类均没有 再次出现在样方中;灌丛中出现的种类仅有金毛狗 和深绿卷柏还继续存在;次生林中出现的崇澍蕨、柄 叶鳞毛薕 (Dryopteris podophylla)、团叶鳞始硕、钝羽 金星蕨、镰叶瘤足蕨、粗叶卷柏等也还继续存留在样 方中, 其中崇澍蕨还继续保持着优势地位。新出现 的大片复叶耳蕨 (Arachniodes cavalerii)、全缘凤尾蕨 (Pteris insignis) 、黑杪椤、广西长筒蕨 (Selenodesmium siamense) 等均为能耐受较强的郁闭度但对人为干扰 比较敏感, 其中较大型的大片复叶耳蕨和黑杪椤在 林下具有一定的优势。

2.2 植被演替过程中蕨类植物 $\boldsymbol{\alpha}$ 多样性的变化 应类植物在草丛、灌丛、次生林、原生林中的物 
种数量依次为 6 种、 11 种、12 种和 13 种(表 1 ,表 3 )。也就是说，随着植被由草丛到原生林演替的进 展, 䓲类植物的物种多样性变得越来越丰富。这与 森林群落演替中物种多样性变化的一般规律相吻合 ( 余作岳和彭少麟，1996），即随着演替的进展，群落 中的物种多样性逐渐增加。群落中的蕨类植物的总 个体数在植被各演替阶段并无明显的变化趋势，原 生林中最多，草丛中的个体数次之，灌丛和次生林的 最少且两者相差无几。这种现象的出现是由于蕨类 植物自身的生物学特性所致，如在草丛中的某些蕨 类如芒萁的极度发展成优势种, 其重要值占草丛中 蕨类植物重要值总和的 $47.88 \%$ 。

但随着演替的进展，䓲类植物群落的多样性指 数、生态优势度和均匀度并不伴随着群落的丰富度 呈明显的规律性变化。在草丛中, 各种指数均具有 最低值，而在灌丛中达到最高值，在次生林和原生林 中依次降低。其原因可能是从草丛到灌丛,由于灌 木的入侵，改变了草地单一的生境，出现了适应烣类 植物生存的荫蔽、阳性环境等多种异质化生境，使得 灌丛中多样性指数、生态优势度和均匀度均达到最 大值。随着演替的进展，乔木树种的侵入增加了林 冠层的郁闭度, 原有的多样化环境逐渐变为单一的
阴湿环境，抑制了蕨类植物在林下的复杂化进程 ( 余作岳和彭少麟, 1996), 因而各种多样性指数也 逐渐降低。

蕨类植物的这种多样性演替格局反映了蕨类植 物物种多样性与所有植物物种多样性变化有相似 性，但因蕨类仅是一个寓居森林下层( 少量成为层 间植物) 的类群，因此其生物多样性又有独特性。 在演替系列中，一般植物物种多样性最高出现在次 顶极群落中, 而蕨类植物在较早的灌丛阶段就出现 了明显较高的多样性。这是因为一些阳性、阴性和 耐荫性薕类植物都可以在灌丛中找到适宜的生态 位，所以单位面积灌丛中蕨类植物种类较多，但由于 不同地方灌丛植被环境的异质性不高, 不同灌丛中 蕨类植物种类组成比较相似。这也许与人们对灌丛 植被中植物物种多样性的传统认识不同，人们对生 物多样性保护的焦点往往放在人为干扰较少的原生 植被中，而忽略了人类干扰频繁、植物物种多样性相 对较低的灌丛植被。实际上,许多珍稀的蕨类植物 就生长在灌丛植被中，如产于我国海南的濒危彍类 二歧莎草蕨 (Schizaea dichotoma) 就生长在海边灌丛 中。虽然经历了频繁的山火和过度的人为干扰，香 港的灌丛植被中依然保存有很多稀有的蕨类

表 3 植被演替过程中蕨类植物群落的多样性指数

Table $3 \alpha$-diversity index in the succession process of vegetation

\begin{tabular}{|c|c|c|c|c|c|c|}
\hline $\begin{array}{c}\text { 植被类型 } \\
\text { Vegetation type }\end{array}$ & $\begin{array}{c}\text { 丰富度 } \\
\text { Richness }\end{array}$ & $\begin{array}{c}\text { 多度 } \\
\text { Abundance }\end{array}$ & $\begin{array}{c}\text { 多样性指数 } \\
\text { Shannon-Weiner } \\
\text { index }\left(H^{\prime}\right)\end{array}$ & $\begin{array}{c}\text { 优势度指数 } \\
\text { Simpson index } \\
\left(D^{\prime}\right)\end{array}$ & $\begin{array}{c}\text { 均匀度指数 } \\
\text { Evenness } \\
\operatorname{index~}\left(J_{s w}\right)\end{array}$ & $\begin{array}{c}\text { 均匀度指数 } \\
\text { Evenness index } \\
\left(J_{g i}\right)\end{array}$ \\
\hline 草丛 Grassland & 6 & 450 & 0.9162 & 0.4334 & 0.5113 & 0.5201 \\
\hline 灌丛 Shrub & 11 & 251 & 2.0721 & 0.8556 & 0.8641 & 0.9412 \\
\hline 次生林 Secondary forest & 12 & 237 & 2.0064 & 0.8279 & 0.8074 & 0.9032 \\
\hline 原生林 Primary forest & 13 & 583 & 1. 7097 & 0.725 & 0.6665 & 0.7854 \\
\hline
\end{tabular}

表 4 植被演替过程中蕨类植物的叶质变化

Table 4 Changes of the leaf characteristics in the succession process of vegetation

\begin{tabular}{|c|c|c|c|c|c|c|c|c|c|}
\hline \multirow{2}{*}{$\begin{array}{c}\text { 植被类型 } \\
\text { Vegetation type }\end{array}$} & \multicolumn{3}{|c|}{$\begin{array}{c}\text { 具草质叶的蕨类植物 } \\
\text { Ferns with herbaceous leaf }\end{array}$} & \multicolumn{3}{|c|}{$\begin{array}{l}\text { 具革质叶的蕨类植物 } \\
\text { Ferns with leathery leaf }\end{array}$} & \multicolumn{3}{|c|}{$\begin{array}{c}\text { 具膜质叶的蕨类植物 } \\
\text { Ferns with membranous leaf }\end{array}$} \\
\hline & $\begin{array}{l}\text { 种数 } \\
\text { No. of } \\
\text { species }\end{array}$ & $\begin{array}{c}\text { 比例 } \\
\% \text { of all } \\
\text { species }\end{array}$ & $\begin{array}{c}\text { 重要值比例 } \\
\% \text { of } \\
\text { total } I V\end{array}$ & $\begin{array}{l}\text { 种数 } \\
\text { No. of } \\
\text { species }\end{array}$ & $\begin{array}{c}\text { 比例 } \\
\% \text { of all } \\
\text { species }\end{array}$ & $\begin{array}{c}\text { 重要值比例 } \\
\% \text { of } \\
\text { total } I V\end{array}$ & $\begin{array}{l}\text { 种数 } \\
\text { No. of } \\
\text { species }\end{array}$ & $\begin{array}{c}\text { 比例 } \\
\% \text { of all } \\
\text { species }\end{array}$ & $\begin{array}{c}\text { 重要值比例 } \\
\% \text { of } \\
\text { total } I V\end{array}$ \\
\hline 草丛 Grassland & 3 & 60.00 & 43.31 & 2 & 40.00 & 56.69 & 0 & 0 & 0 \\
\hline 灌丛 Shrub & 7 & 63.64 & 60.71 & 4 & 36.36 & 39.29 & 0 & 0 & 0 \\
\hline 次生林 Secondary forest & 8 & 66.67 & 62.66 & 4 & 33.33 & 37.34 & 0 & 0 & 0 \\
\hline 原生林 Primary forest & 8 & 61.54 & 58.78 & 4 & 30.77 & 36.15 & 1 & 7.69 & 5.07 \\
\hline
\end{tabular}


( Dudgeon \& Corlertt , 1994 ; Hu , 2003 )。

2.3 植被演替过程中蕨类植物叶质的变化

植物叶片的质地主要与生境的水分条件有关， 不同质地的植物叶片反映了植物对生境水分的适应 情况。从表 1 、表 4 可以看出，从草丛、灌丛、次生林 到原生林植被的恢复过程中，具革质叶的蕨类在各 阶段的比例分别为 $40.00 \% 、 36.36 \% 、 33.33 \%$ 、 $30.77 \%$,所占的重要值比例分别为 $56.70 \%$ 、 $39.28 \% 、 37.34 \% 、 36.15 \%$,有逐渐减少的趋势; 而 具草质叶的蕨类在各阶段的比例分别为 $60.00 \%$ 、 $63.64 \% 、 66.67 \% 、 61.54 \%$,所占的重要值比例分别 为 $43.31 \% 、 60.71 \% 、 62.66 \% 、 58.78 \%$, 有逐渐增 加的趋势。在演替的最后阶段，出现了具有膜质叶 的广西长筒䓲。结果表明, 随着演替的进展和群落 环境的中生化, 适应强光、干旱环境的具革质叶的蕨 类逐渐被适应阴湿环境的具草质叶的蕨类所代替。

\section{4 植被演替过程中蕨类植物耐荫性的变化}

植物的耐荫性是植物对光照环境的反映, 不同 的环境中阴性植物、耐荫性植物和阳性植物的比例 不同。在表 1 、表 5 中 随着群落演替的进展, 草丛、 灌丛、次生林、原生林各阶段植被中出现的阴性蕨类 植物的比例 ( $16.87 \% 、 18.18 \% 、 58.33 \% 、 76.92 \%)$ 和所占的重要值比例 $(6.08 \% 、 22.81 \% 、 70.03 \%$ 、 $85.23 \%)$ 不断增多; 而阳性植物比例依次为 $66.67 \% 、 54.55 \% 、 8.33 \% 、 0$,重要值比例依次为 $81.10 \% 、 59.70 \% 、 3.90 \% 、 0$, 逐渐减少 到有闭度较 高的原生林中则没有出现典型的阳性䓲类植物的分 布。

\section{5 植被演替过程中蕨类植物繁殖对策的变化}

植物的繁殖方式是生态对策的重要组成部分。 䕋类植物的主要繁殖方式是通过孢子传播进行有性
繁殖，但通过根状茎延长、产生芽孢等方式进行无性 繁殖也很普遍。目前, 有关不同生境中䓲类植物繁 殖策略的选择在国内外尚未见报道。根状茎短而直 立或斜升或横卧的蕨类植物一般为有性繁殖, 而根 状茎长而横走或具有芽孢的蕨类植物虽然能够进行 有性繁殖, 但同一群落内的种群主要通过无性繁殖 来扩增。

从表 1 、表 6 可知，在草丛、灌丛、次生林、原生 林 4 个阶段, 进行有性繁殖的偋类植物所占的比例 分别为 $33.33 \% 、 36.36 \% 、 50 \% 、 61.54 \%$,重要值比 例分别为 $14.89 \% 、 43.58 \% 、 45.15 \% 、 54.26 \%$, 具 有逐渐增高的趋势; 可进行无性繁殖的䓲类植物在 各阶段的比例分别为 $66.67 \% 、 63.64 \% 、 50.00 \%$ 、 $38.46 \%$,重要值比例分别为 $85.11 \% 、 56.42 \%$ 、 $54.85 \% 、 45.74 \%$ 随着演替的进展而逐渐降低。

在逆境中当有性繁殖难以实现时, 营养繁殖是 植物应对不利条件的重要对策( Hara，1987; Koop， 1987 ; 贺金生等，1999)。草丛和灌丛中的大部分 蕨类 (如芒萁、铺地蜈蚣等) 是地被的先锋植物，日 照强烈、环境干燥、高温低湿、日夜温差大不利于其 狍子繁殖, 只能靠根状茎不断伸展曼延等无性繁殖 的方式来完成种群数量的扩增, 因而在演替的早期 阶段, 蕨类植物主要是通过无性繁殖以扩大种群数 量。而在次生林、原生林中, 随着群落环境的中生 化, 群落郁闭度增加, 土壤水分条件改善, 有利于疹 类植物的狍子萌发, 因而进行无性繁殖的藃类植物 在林中逐渐稀少 取而代之的是进行有性繁殖的蕨 类植物。

但这种情况只是彍类植物生活史对策选择的一 般趋势, 也有一些䓲类植物对环境变化的生活史反 应对策与此不同，如稀子蕨属(Monachosorum)、实硕

表 5 植被演替过程中蘐类植物的耐荫性变化

Table 5 The changes in the shade tolerance of ferns in the succession process of vegetation

\begin{tabular}{|c|c|c|c|c|c|c|c|c|c|}
\hline \multirow{2}{*}{$\begin{array}{c}\text { 植被类型 } \\
\text { Vegetation type }\end{array}$} & \multicolumn{3}{|c|}{$\begin{array}{l}\text { 阳性蕨类 } \\
\text { Sun ferns }\end{array}$} & \multicolumn{3}{|c|}{$\begin{array}{c}\text { 耐荫蕨类 } \\
\text { Shade-enduring ferns }\end{array}$} & \multicolumn{3}{|c|}{$\begin{array}{l}\text { 阴性蕨类 } \\
\text { Shade ferns }\end{array}$} \\
\hline & $\begin{array}{l}\text { 种数 } \\
\text { No. of } \\
\text { species }\end{array}$ & $\begin{array}{c}\text { 比例 } \\
\% \text { of all } \\
\text { species }\end{array}$ & $\begin{array}{c}\text { 重要值比例 } \\
\% \text { of } \\
\text { total } I V\end{array}$ & $\begin{array}{l}\text { 种数 } \\
\text { No. of } \\
\text { species }\end{array}$ & $\begin{array}{c}\text { 比例 } \\
\% \text { of all } \\
\text { species }\end{array}$ & $\begin{array}{c}\text { 重要值比例 } \\
\% \text { of } \\
\text { total } I V\end{array}$ & $\begin{array}{l}\text { 种数 } \\
\text { No. of } \\
\text { species }\end{array}$ & $\begin{array}{c}\text { 比例 } \\
\% \text { of all } \\
\text { species }\end{array}$ & $\begin{array}{c}\text { 重要值比例 } \\
\% \text { of } \\
\text { total } I V\end{array}$ \\
\hline 草丛 Grassland & 4 & 66.67 & 81.10 & 1 & 16.67 & 12.82 & 1 & 16.67 & 6.08 \\
\hline 灌丛 Shrub & 7 & 63.64 & 59.70 & 2 & 18.18 & 17.49 & 2 & 18.18 & 22.81 \\
\hline 原生林 Primary forest & 0 & 0 & 0 & 3 & 23.08 & 14.77 & 10 & 76.92 & 85.23 \\
\hline
\end{tabular}


表 6 植被演替过程中茨类植物的繁殖对策的变化

Table 6 The reproduction strategy of ferns in the succession process of vegetation

\begin{tabular}{|c|c|c|c|c|c|c|}
\hline \multirow{2}{*}{$\begin{array}{c}\text { 植被类型 } \\
\text { Vegetation type }\end{array}$} & \multicolumn{3}{|c|}{$\begin{array}{c}\text { 有性繁殖的蕨类植物 } \\
\text { Sexual reproduction fern }\end{array}$} & \multicolumn{3}{|c|}{$\begin{array}{c}\text { 无性/有性繁殖的蕨类植物 } \\
\text { Asexual/sexual reproduction fern }\end{array}$} \\
\hline & $\begin{array}{l}\text { 种数 } \\
\text { No. of } \\
\text { species }\end{array}$ & $\begin{array}{c}\text { 比例 } \\
\% \text { of } \\
\text { all species }\end{array}$ & $\begin{array}{c}\text { 重要值比例 } \\
\% \text { of } \\
\text { total } I V\end{array}$ & $\begin{array}{l}\text { 种数 } \\
\text { No. of } \\
\text { species }\end{array}$ & $\begin{array}{c}\text { 比例 } \\
\% \text { of } \\
\text { all species }\end{array}$ & $\begin{array}{c}\text { 重要值比例 } \\
\% \text { of } \\
\text { total } I V\end{array}$ \\
\hline 草丛 Grassland & 2 & 33.33 & 14.89 & 4 & 66.67 & 85.11 \\
\hline 灌丛 Shrub & 4 & 36.36 & 43.58 & 7 & 63.64 & 56.42 \\
\hline 原生林 Primary forest & 8 & 61.54 & 54.26 & 5 & 38.46 & 45.74 \\
\hline
\end{tabular}

属 (Bolbitis) 和耳䓲属 (Polystichum) 的一些种类, 它 们多生长在发育好的森林，往往通过出芽等方式来 完成种群扩增。但偋类植物这种生活史对策与垬桐 (Davidia involucrata)（沈泽昊等，1999）、米心水青 冈(Fagus engleriana) (贺金生等，1999) 等许多种子 植物不同，后者在郁闭的成熟林中选择无性繁殖对 策, 而在开阔的幼林中选择有性繁殖对策。䓲类植 物生活史对策是蓱类植物不同种类本身的固有习 性, 目前尚没有薑类植物在不同植被演替阶段改变 个体的生态对策的报道。本研究中蕨类植物生活史 对策在不同植被发育阶段的差异是群落环境变化对 蕨类植物群体适应性的改变, 而不是个体适应对策 的调整。

\section{3 结论}

植物群落的演替常常被看作遭受某种破坏的一 个群落逐渐恢复为没有破坏时的外貌的过程 (Horn, 1980;Krebs ,2003)。在群落演替过程中，也 就是群落环境中生化的过程中, 水分、光照、土壤、地 形、生物等生态因子的变化及其相互作用是十分复 杂的，群落中总体物种多样性在达到顶极群落前是 不断增加的。但草本层的物种多样性变化较无规律 可循, 与乔木层、灌木层的变化并不同步, 草本层依 附于乔木层的波动而不能独立反映整个群落的演替 趋势 ( 余作岳和彭少麟, 1996)。在广东古悓山自然 保护区群落的发生和发展过程中, 颜类植物的物种 丰富度不断增加 结合具有不同叶质、不同耐荫性和 不同繁殖对策的㣒类在植被恢复过程中的变化, 说

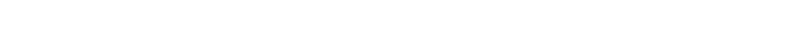
能力对于其所在的植被环境具有比较显著的指示作 用, 是反映环境因子变化的良好指标。但这一结果
是植被演替过程中的普遍规律还是 草本层的物种 多样性变化较无规律可循” 的例证, 还有待进一步 研究。此外，取样面积的大小、取样技术的随机性、 演替系列中样地地形、海拔、坡度、坡向等环境条件 均有可能对结果产生影响。蕨类植物能否独立反映 整个群落的演替趋势, 尚有待于今后进一步探讨。

在广东古兒山自然保护区群落的发生和发展过 程中,䓲类植物一方面在积极、有效地改造环境条 件，另一方面也在不断适应新的被改变了的环境条 件。由于茨类植物生长密集、覆盖度大、根系密接成 网，可以有效地改造群落的水分、土壤、营养和光照 条件 对群落的发生和演替具有重要意义。随着群 落环境条件的改变, 蕻类植物的多样性组成及其地 位也在不断发生变化。因此我们在植被保护和植被 恢复的实际工作中，必须注意森林乔木树种与林下 蕨类植物的配置情况，忽视它们之间的相生相克作 用将会给我们的实践工作带来不必要的损失。如我 们在种植桉树 (Eucalyptus) 林时, 由于桉树与本地蓱 类植物缺乏互利关系 林下往往很难生长䲞类植物， 这会给生物多样性保护工作造成损失;而我们在种 植马尾松 (Pinus massoniana) 及其他乡土树种, 却往 往与林下的芒其发生互惠关系, 有利于植被的恢复 和保护。

蕨类植物多样性是生物多样性的重要组成部 分, 保护生物多样性不能忽视硕类植物。我们在制 订生物多样性保护规划时，不仅要考虑保护物种多 样性较丰富的原始林和次生林, 而且也不能忽略演 替系列中其他各个阶段生态系统的保护工作。当 然, 首先要重点保护物种多样性相对丰富、生态效应 相对较高的处于演替后期阶段的生态系统。 


\section{参考文献}

Daubenmire, R. ( Translated by Chen, Q. C. (陈庆诚)). 1981. Plant Communities - a Textbook of Plant Synecology (植物群落一一植物群落生态学教程). People' s Education Press, Beijing, 113 -301. (in Chinese)

Dong, M. (董鸣) . 1996. Clonal growth in plants in relation to resource heterogeneity: foraging behavior. Acta Botanica Sinica (植物学报), 38: $828-835$. (in Chinese with English abstract)

Dudgeon, D. and Corlertt, R. 1994. Hills and Streams: an Ecology of Hong Kong. Hong Kong University Press, Hong Kong, 1 - 234.

Guan, D. S. (管东生). 1996. A study of nutrients in fernland of Hong Kong. Acta Phytoecologica Sinica (植物生态学 报), 20: 235 - 244. (in Chinese with English abstract)

Guo, Q. S. (郭泉水). 1998. The layer composition and construction of life form of the plants in major Chinese forest communities. In: Jiang, Y. X. (蒋有绪), Guo, Q. S. (郭泉水) and Ma, J. (马娟) (eds.), The Taxonomy and Characters of the Major Chinese Forest Communities (中国 森林群落分类及其群落学特征). Science Press \& China Forestry Publishing House, Beijing, 179 - 306. (in Chinese)

Hara, M. 1987. Analysis of seedling banks of a climax beech forest: ecological importance of seedling sprouts. Vegetatio, 71: $67-74$.

He, J. S. (贺金生), Lin, J. (林洁) and Liu, F. (刘峰). 1998. Study on the sprouting process of Fagus engleriana in Shennongjia Mountains. Acta Phytoecologica Sinica (植 物生态学报), 22: 385 - 391. (in Chinese with English abstract)

Horn, H. S. (Translated by Hu, S. S. (胡舜士)). 1980. Succession. In: May, R. M. (ed.). Theoretical Ecology: Principle and Applications (理论生态学). Science Press, Beijing, 188 - 204. ( in Chinese)

Hu, Q. M. (胡启明). 2003. Rare and Precious Plants of Hong Kong. Agriculture, Fisheries and Conservation Department of Hong Kong, Hong Kong, 1 - 234. ( in Chinese and in English)

Johnson-Maynard, J. L., McDaniel, P. A., Ferguson, D. E. and Falen, A. L. 1998. Changes in soil solution chemistry of andisols following invasion by bracken fern. Soil Science, 163: $814-821$.

Johnson-Maynard, J. L., McDaniel, P. A., Ferguson, D. E. and Falen, A. L. 1997. Chemical and mineralogical conversion of andisols following invasion by bracken fern. Soil
Science Society of America Journal, 61: 549 - 555.

Koop, H. 1987. Vegetative reproduction of trees in some European natural forests. Vegetatio, 72: $103-110$.

Krebs, C. J. 2003. Ecology: the Experimental Analysis of Distribution and Abundance (5th edn.) (生态学). Science Press, Beijing, $403-433$.

Ma，K. P. (马克平). 1994. The measurement of community diversity. In: Qian, Y. Q. (钱迎倩) and Ma, K. P. (马 克平) (eds.), Principles and Methodologies of Biodiversity Studies (生物多样性研究的原理与方法). Chinese Science and Technology Press, Beijing, 141 - 163. (in Chinese)

Pielou, E. C. 1975. Ecological Diversity. John Wiley \& Sons Inc., New York, 1-165.

Shen, Z. H. (沈泽昊), Lin, J. (林洁), Chen, W. L. (陈 伟烈) and Jin, Y. X. (金义兴). 1999. Structure and regeneration of Davidia involucrata communities at Wolong region, Sichuan Province. Acta Phytoecologica Sinica (植 物生态学报), 23: 562 - 567. (in Chinese with English abstract)

Soares, M. L. G. 1999. Structure and degree of perturbation of mangroves at Tijuca Lagoon, Rio de Janeiro, RJ Brazil. Revista Brasileira de Biologia, 59: 503 - 515.

Sun, R. Y. (孙儒泳), Li, B. (李博), Zhuge, Y. (诸葛阳) and Shang, Y. C. (尚玉昌). 1993. General Ecology (普 通生态学). China Higher Education Press, Beijing, 1 324. (in Chinese)

Whittaker, R. H. 1960. Vegetation of Siskiyou Mountains, Oregon and California. Ecological Monographs, 30: 279 338.

Whittaker, R. H. 1972. Evolution and measurement of species diversity. Taxon, 21:213-251.

Yorks, T. E., Leopold, D. J. and Raynal, D. J. 2000. Vascular plant propagule banks of six eastern hemlock stands in the Catskill Mountains of New York. Journal of the Torrey Botanical Society, 127: 87 - 93.

Yu, Z. Y. (余作岳) and Peng, S. L. (彭少麟). 1996. Ecological Studies on Vegetation Rehabilitation of Tropical and Subtropical Degraded Ecosystems (热带亚热带退化生态系 统植被恢复生态学研究). Guangdong Science and Technology Press, Guangzhou, $1-266$. (in Chinese)

Zhang, D. J. (张笃见), Ye, X. Y. (叶晓娅) and You, W. H. (由文辉) . 1999. Evergreen broad-leaved forest floor in Tiantong, Zhejiang Province. Acta Phytoecologica Sinica (植物生态学报), 23: 544 - 556. (in Chinese with English abstract) 